\title{
Lung clearance index predicts pulmonary exacerbations in young patients with cystic fibrosis
}

\author{
François Vermeulen, Marijke Proesmans, Mieke Boon, Trudy Havermans, Kris De Boeck
}

\begin{abstract}
- Additional material is published online only. To view please visit the journal online (http://dx.doi.org/10.1136/ thoraxjnl-2013-203807).

Department of Pediatrics, Cystic Fibrosis Centre, University Hospital Leuven, Leuven, Belgium

\section{Correspondence to} Dr François Vermeulen, Pediatric Pulmonology, CF Centre, University Hospital Leuven, Herestraat, 49, Leuven B-3000, Belgium; Francois. vermeulen@uzleuven.be
\end{abstract}

Received 29 April 2013 Revised 29 July 2013 Accepted 1 August 2013 Published Online First 10 September 2013
To cite: Vermeulen $F$, Proesmans $\mathrm{M}$, Boon $\mathrm{M}$, et al. Thorax 2014;69:39-45.

\begin{abstract}
Rationale The lung clearance index $(L C I)$ is a promising endpoint for use in cystic fibrosis (CF) clinical trials, but correlations with validated clinical endpoints have not yet been established.

Objective This study aimed to demonstrate that, in young patients with $\mathrm{CF}$, baseline $\mathrm{LCl}$ predicts subsequent pulmonary exacerbation (PE) and correlates with the respiratory domain of the CF Questionnaire-Revised (CFQ- Resp $_{\text {res }}$ ).

Methods Baseline $\mathrm{LCl}$, forced expiratory volume in $1 \mathrm{~s}$ $\left(F E V_{1}\right), C F Q-R_{\text {resp }}$ and PEs over the subsequent year were prospectively recorded in 63 patients aged 5-19 years. The ability of baseline $\mathrm{LCl}$ to predict PE was assessed using negative binomial regression models and KaplanMeier plots.
\end{abstract}

Results Twenty-six patients (41\%) experienced 48 PEs. Baseline $\mathrm{LCl}$ and $\mathrm{FEV}_{1}$ were predictors of PE. Compared with the quartile with the lowest $\mathrm{LCl}$, the annual PE rate in increasing $\mathrm{LCl}$ quartiles was $2.9(95 \% \mathrm{Cl} 0.5$ to 16.5 , $\mathrm{p}=0.238), 5.4(95 \% \mathrm{Cl} 1.0$ to $29.0, \mathrm{p}=0.045)$ and 13.6 $(95 \% \mathrm{Cl} 2.8$ to $67.1, \mathrm{p}=0.001)$. Similarly, time to first $\mathrm{PE}$ decreased with worsening $\mathrm{LCl}$ quartiles (log-rank test for trend, $p<0.001)$. Furthermore, $\mathrm{LCl}$ correlated with CFQ- $R_{\text {resp }}(r=-0.43, p<0.001)$. In the subgroup of 53 patients with normal $\mathrm{FEV}_{1}, \mathrm{LCl}$ was a predictor of PE. In this subgroup, $\mathrm{LCl}$ also correlated with CFQ- $\mathrm{R}_{\text {resp }}$ $(r=-0.282, p=0.043)$.

Conclusions Baseline $\mathrm{LCl}$ predicts PE in young patients with CF and correlates with CFQ- $R_{\text {resp, }}$ a validated patient-reported outcome, even in the subgroup with normal FEV ${ }_{1}$. These data further support the use of $\mathrm{LCl}$ as a surrogate outcome measure in CF clinical trials.

\section{INTRODUCTION}

Forced expiratory volume in $1 \mathrm{~s}\left(\mathrm{FEV}_{1}\right)$ is currently the only accepted surrogate endpoint for use in cystic fibrosis (CF) clinical trials. As most patients with $\mathrm{CF}$ have a normal $\mathrm{FEV}_{1}$ until adolescence, $\mathrm{FEV}_{1}$ is an insensitive endpoint for this age group. ${ }^{1}$ New surrogate endpoints are therefore needed. The lung clearance index (LCI), an index of ventilation homogeneity derived from the multiple breath washout (MBW) of an inert gas, is one candidate surrogate endpoint, as is chest CT.

The LCI satisfies many of the conditions needed to qualify as a surrogate endpoint. It is feasible in a 'standard' clinical setting ${ }^{2}{ }^{3}$ and can be measured repeatedly without harm. The measurement technique was recently standardised, ${ }^{4}$ and commercially available devices have been validated. ${ }^{5}$ Furthermore, the short- and medium-term repeatability are good in both healthy subjects and patients, ${ }^{7}$ and the LCI is

\section{Key messages}

What is the key question?

- The lung clearance index $(\mathrm{LCl})$ is a marker of early cystic fibrosis (CF) lung disease proven to be sensitive, repeatable and responsive to interventions. However, before the $\mathrm{LCl}$ can be used as a surrogate endpoint in trials involving patients with $\mathrm{CF}_{\text {, a correlation with clinically }}$ meaningful endpoints such as pulmonary exacerbation or patient-reported outcomes has to be established.

\section{What is the bottom line?}

- In young patients with $\mathrm{CF}$, baseline $\mathrm{LCl}$ predicts the time to the first pulmonary exacerbation in the 12 months after baseline assessment. The $\mathrm{LCl}$ also correlates with CFQ- $\mathrm{R}_{\text {respr }}$ a validated patient-reported outcome.

\section{Why read on?}

- This prospective work demonstrates the link between the $\mathrm{LCl}$ and two clinically meaningful endpoints in young patients with CF: pulmonary exacerbations and CFQ- $\mathrm{R}_{\text {resp. }}$. This contributes to the validation of the $\mathrm{LCl}$ as a surrogate endpoint for use in clinical trials.

more sensitive than $\mathrm{FEV}_{1}$ for detecting early CF lung disease in cross-sectional analyses. ${ }^{8}{ }^{9}$ The LCI is also responsive to interventions such as treatments with intravenous antibiotics, ${ }^{10}$ hypertonic saline ${ }^{11}$ or rh-DNAse, ${ }^{12}$ and it was used successfully as an endpoint in a trial evaluating the effect of hypertonic saline in infants. ${ }^{13}$ In addition, the LCI was shown to be improved in young children with mild CF lung disease carrying at least one G551D mutation who were treated with ivacaftor. ${ }^{14}$ Initial data concerning the correlation between the LCI and long-term disease course have emerged, and abnormal LCI values in preschool children with $\mathrm{CF}$ were shown to predict spirometric abnormalities at school age. ${ }^{15}$

To validate a physiological measurement as a surrogate endpoint it should be demonstrated that it is correlated with validated clinical outcomes such as survival or, in the case of CF, pulmonary exacerbations (PEs) or patient-reported outcome measures.

The aim of this study was therefore to investigate the relationship between baseline LCI and 
subsequent PE, patient-reported outcome measures and symptoms as a further step in the validation of the LCI as a surrogate endpoint for clinical trials in patients with CF.

Our first hypothesis was that the baseline LCI would predict subsequent PEs during the year after the baseline measurements. Our second hypothesis was that the LCI would correlate with patient-reported outcome measures and symptom scores. Because the LCI is more sensitive than $\mathrm{FEV}_{1}$ for detecting early lung disease in CF, the LCI was expected to be a predictor of $\mathrm{PE}$ and to correlate with patient-reported outcome measures even in the subgroup of patients with normal $\mathrm{FEV}_{1}$.

Some of the results of this study have been previously reported in the form of an abstract. ${ }^{16}$

\section{METHODS}

\section{Recruitment}

In this prospective single-centre study, patients with $\mathrm{CF}$ aged between 5 and 20 years were recruited during routine outpatient visits between January 2011 and October 2012. Patients infected with methicillin-resistant Staphylococcus aureus (MRSA) or Burkholderia cepacia are not allowed in the standard lung function laboratory and were excluded.

Control subjects, recruited by advertisement, had no history of chronic respiratory symptoms and had not suffered respiratory infections in the previous 4 weeks.

The study was approved by the ethics committee of the University of Leuven. Caregivers and/or patients gave written informed consent before inclusion.

\section{Multiple breath washout (MBW) measurement}

A detailed description of MBW measurements and quality control is shown in the online supplement.

Nitrogen MBW was performed using the Exhalyzer D (EcoMedics AG, Duernten, Switzerland), as described elsewhere. ${ }^{3}$ Before spirometry and after inhalation of $400 \mu \mathrm{g}$ salbutamol, MBW measurements were performed with a between-test delay of more than twice the washout time of the previous measurement.

\section{$\mathrm{LCl}$ calculations and repeatability criteria}

An MBW measurement was excluded if significant leaks, sighs or irregular breathing occurred or if the functional residual capacity (FRC) differed by more than 20\% compared with the largest FRC of the valid measurements within the same session. The mean LCI of all valid MBW measurements was used.

Z-scores were calculated from the values in the control group. An LCI z-score of $>2$ was considered abnormal.

\section{Spirometry and biometry}

$\mathrm{FEV}_{1}$, forced vital capacity (FVC) and forced expiratory flow between $25 \%$ and $75 \%$ of $\mathrm{FVC}\left(\mathrm{FEF}_{25-75}\right)$ were expressed as the percent predicted or as z-scores using reference equations from the Global Lung Function Initiative. ${ }^{17} \mathrm{~A}$ z-score lower than -2 was considered abnormal.

Height, weight and body mass index were expressed as $\mathrm{z}$-scores according to local reference equations. ${ }^{18}$

\section{Pulmonary exacerbations}

The time to the first PE and the number of PEs during the 12 months following the baseline LCI measurement were recorded. PEs were defined as changes in respiratory status for which intravenous antibiotics were administered. Intravenous antibiotic therapy was prescribed by the CF consultant in accordance with current practice guidelines. ${ }^{19}$ The LCI results were not disclosed to the clinicians.
Patient-reported outcome and symptom score

Before any other procedure, each child ( $\geq 12$ years) or parent ( $<12$ years) completed the respiratory domain of the CF Questionnaire-Revised (CFQ- $\left.\mathrm{R}_{\text {resp }}\right){ }^{20}{ }^{21}$ The CFQ- $R_{\text {resp }}$ was standardised to range from 0 to 100 , with high scores indicating fewer respiratory symptoms.

The CF Clinical Score (CFCS) ${ }^{10} 22$ is a composite score including symptoms and clinical findings assessed by the CF consultant and ranges from 10 (mildest symptoms and signs) to 50 (most severe symptoms and signs).

Both assessments were taken on the same day as the MBW measurement and the spirometry.

\section{Statistical analysis}

The LCI, spirometric parameters, CFQ- $\mathrm{R}_{\text {resp }}$ and CFCS were divided into quartiles. The time to subsequent $\mathrm{PE}$ was compared between quartiles using Kaplan-Meier plots and the log-rank test for trend.

The predictive value of age, gender, infection with Pseudomonas aeruginosa, LCI z-score, $\mathrm{FEV}_{1}$ z-score, $\mathrm{FEF}_{25-75}$ $\mathrm{z}$-score, CFQ- $\mathrm{R}_{\text {resp }}$ and CFCS on annualised PE rate was evaluated using univariate and multivariate negative binomial regression models.

Correlations between parameters were assessed by Spearman correlation coefficient (r).

SPSS V.21.0 (IBM, Armonk, New York, USA) was used for the statistical analyses.

\section{RESULTS}

\section{Study population}

Of the 86 eligible 5-19-year-old patients with CF in follow-up at the Leuven CF Centre, 63 were enrolled. The reasons for not participating included patient not approached by the staff $(n=13)$, infection with $B$ cepacia and/or MRSA $(n=5)$, inability to obtain a valid MBW measurement $(n=3)$ or refusal by the patient $(n=2)$. There were no differences in age, weight, height, body mass index, spirometry, pancreatic status, proportion of F508del homozygotes or colonisation status for $P$ aeruginosa between patients who were or were not enrolled (table 1).

Of the 61 enrolled control subjects, three were excluded due to inability to perform the MBW measurement and one because of suspicion of subclinical lung disease (Ehler-Danlos syndrome). Compared with the patients with CF, the control subjects had a similar age distribution but a greater z-score for weight, height, $\mathrm{FEV}_{1}$ and $\mathrm{FEF}_{25-75}$ and a lower LCI z-score (table 1).

\section{Correlation between $\mathrm{LCl}_{1} \mathrm{FEV}_{1}$ and $\mathrm{FEF}_{25-75}$}

In the patients with CF there was a negative correlation between the LCI $\mathrm{z}$-score and $\mathrm{FEV}_{1} \mathrm{z}$-score $(\mathrm{r}=-0.642, \mathrm{p}<0.001)$. In 42 of the 63 patients $(67 \%)$ the LCI was abnormal but the $\mathrm{FEV}_{1}$ was normal. Eleven patients (17\%) had a normal LCI and a normal $\mathrm{FEV}_{1}$ and 10 (16\%) had an abnormal LCI and $\mathrm{FEV}_{1}$. None of the patients with an abnormal $\mathrm{FEV}_{1}$ had a normal LCI (figure 1 and online supplementary figure E1). There was a moderate correlation between the LCI and $\mathrm{FEF}_{25-75} \mathrm{z}$-scores $(\mathrm{r}=-0.673, \mathrm{p}<0.001$, see online supplementary figure E2) and a strong correlation between $\mathrm{FEV}_{1}$ and $\mathrm{FEF}_{25-75}$ z-scores $(\mathrm{r}=0.731, \mathrm{p}<0.001)$. Of 53 patients with a normal $\mathrm{FEV}_{1}, 47$ (89\%) also had a normal $\mathrm{FEF}_{25-75}$ and 6 (11\%) had an abnormal $\mathrm{FEF}_{25-75}$. These six patients also had an abnormal LCI (see online supplementary figure E2). 
Table 1 Baseline characteristics of study cohort

\begin{tabular}{|c|c|c|c|}
\hline & \multicolumn{2}{|l|}{ Patients with CF } & \multirow[b]{2}{*}{ Control subjects } \\
\hline & Included & Not included & \\
\hline $\mathrm{N}$ & 63 & 23 & 57 \\
\hline Age in years, median (range) & $12.4(5.3-18.8)$ & $14.0(4.5-19.6)$ & $12.4(4.4-17.9)$ \\
\hline$<12$ years & $31(49 \%)$ & $10(43 \%)$ & $27(47 \%)$ \\
\hline Male & $33(52 \%)$ & $10(43 \%)$ & $28(48 \%)$ \\
\hline F508del homozygote & $40(63 \%)$ & $12(52 \%)$ & \\
\hline Pancreatic sufficient & $6(10 \%)$ & $4(17 \%)$ & \\
\hline \multicolumn{4}{|c|}{ Colonisation status with Pseudomonas aeruginosa† } \\
\hline Chronic & $8(13 \%)$ & $2(9 \%)$ & \\
\hline Intermittent & $12(19 \%)$ & $3(13 \%)$ & \\
\hline Weight z-score & $-0.51(0.94)$ & $-0.40(1.17)$ & $0.04(0.74)^{*}$ \\
\hline Height z-score & $-0.41(0.98)$ & $-0.73(1.21)$ & $0.37(0.98)^{*}$ \\
\hline BMI z-score & $-0.34(0.90)$ & $0.04(0.95)$ & $-0.19(0.69)$ \\
\hline $\mathrm{FEV}_{1} \%$ predicted & $89.4(15.7)$ & $86.3(25.7)$ & $102.7(10.2)^{*}$ \\
\hline $\mathrm{FEV}_{1}$ z-score & $-0.88(1.29)$ & $-1.09(2.10)$ & $0.23(0.85)^{*}$ \\
\hline $\mathrm{FEF}_{25-75} \%$ predicted & $79.9(30.5)$ & $74.3(42.1)$ & $94.3(21.2)^{*}$ \\
\hline $\mathrm{FEF}_{25-75}$ z-score & $-1.04(1.53)$ & $-1.37(2.08)$ & $-0.3(1.0)^{*}$ \\
\hline $\mathrm{LCl}$ & $10.78(3.09)$ & & $7.30(0.50)^{*}$ \\
\hline LCl z-score & $6.97(6.20)$ & & $0.00(1.00)^{*}$ \\
\hline CFQ- $R_{\text {resp }}$ median (range) & $89(34-100)$ & & \\
\hline CFCS, median (range) & $15(10-30)$ & & \\
\hline
\end{tabular}

All control subjects had a normal LCI and a normal FEV 1 . A negative correlation between the LCI z-score and $\mathrm{FEV}_{1}$ $\mathrm{z}$-score was also observed in the controls $(\mathrm{r}=-0.384, \mathrm{p}=0.004)$.

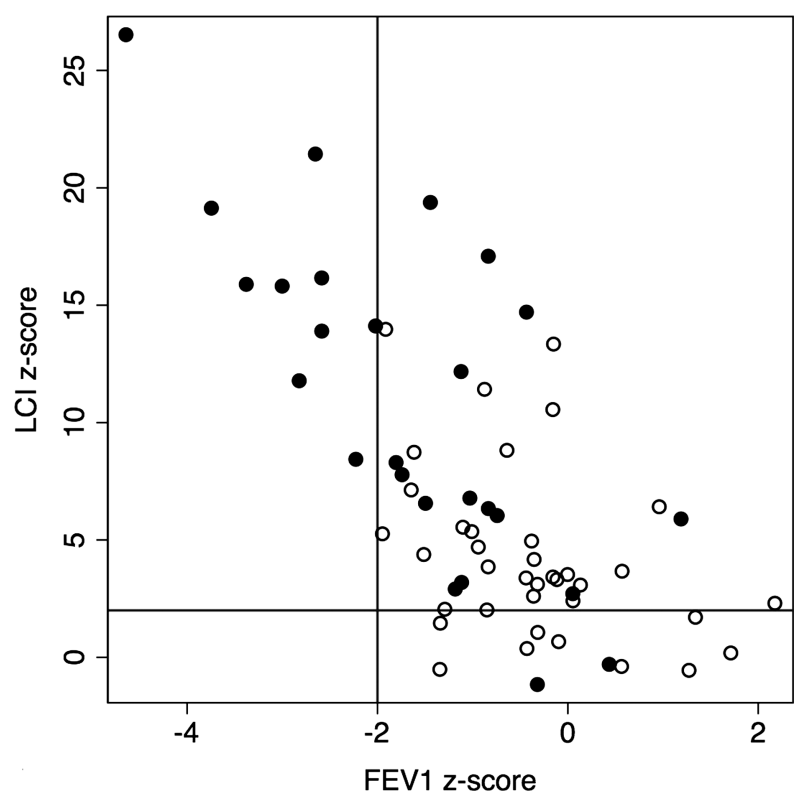

Figure 1 Relationship between the lung clearance index (LCI) z-score and forced expiratory volume in $1 \mathrm{~s}\left(\mathrm{FEV}_{1}\right) \mathrm{z}$-score in patients with cystic fibrosis with subsequent pulmonary exacerbation (closed circles) or without pulmonary exacerbation (open circles). The horizontal line represents the upper limit of normal for the $\mathrm{LCl}$ z-score and the vertical line represents the lower limit of normal for the $\mathrm{FEV}_{1} \mathrm{z}$-score.

\section{Correlation of lung function with CFQ- $\mathrm{R}_{\text {resp }}$ and CFCS}

The LCI $z$-score $(r=-0.431, p<0.001$, figure $2 \mathrm{~A})$ and the $\mathrm{FEF}_{25-75}$ z-score $(\mathrm{r}=0.409, \mathrm{p}=0.001)$ correlated with the CFQ-R $\mathrm{R}_{\text {resp }}$ but the $\mathrm{FEV}_{1} \mathrm{z}$-score $(\mathrm{r}=0.249, \mathrm{p}=0.051$, figure $2 \mathrm{C})$ did not. The LCI $\mathrm{z}$-score also correlated with the CFCS $(\mathrm{r}=0.565, \mathrm{p}<0.001$, figure $2 \mathrm{~B})$, as did the $\mathrm{FEV}_{1} \mathrm{z}$-score $(\mathrm{r}=$ $-0.411, p=0.002$, figure 2D) and $\mathrm{FEF}_{25-75} \mathrm{z}$-score $(\mathrm{r}=0.462$, $\mathrm{p}<0.001)$. A separate analysis of children $(<12$ years) and adolescents ( $\geq 12$ years) showed similar associations (see online supplementary table E1).

When the analysis was restricted to the subgroup of 53 patients with a normal $\mathrm{FEV}_{1}(\mathrm{z}$-score $>-2)$, there remained a correlation between the LCI z-score and CFQ- $\mathrm{R}_{\text {resp }}(\mathrm{r}=-0.282$, $p=0.043$ ) and between the LCI $z$-score and the CFCS $(r=0.445, p=0.002)$, but not between the $F V_{1} z$-score and the CFQ- $\mathrm{R}_{\text {resp }}(\mathrm{r}=0.016, \mathrm{p}=0.908)$ or CFCS $(\mathrm{r}=-0.17, \mathrm{p}=0.260)$.

\section{Pulmonary exacerbations}

Of the 63 patients, $26(41 \%)$ received a total of 48 courses of intravenous antibiotics for a PE in the follow-up period after the baseline LCI measurement. Follow-up time was 365 days for 60 patients and 349, 223 and 177 days for the three other patients. The time to the first PE decreased with worsening LCI quartile $(p<0.001$, figure $3 \mathrm{~A})$ and worsening $\mathrm{FEV}_{1} \mathrm{z}$-score quartile $(p=0.002$, figure $3 \mathrm{~B})$ or $\mathrm{FEF}_{25-75} \mathrm{z}$-score quartile $(\mathrm{p}=0.001$, see online supplementary figure E3A). The time to the first PE also decreased with worsening CFQ- $R_{\text {resp }}$ quartile $(p=0.001$, see online supplementary figure E4A) and with worsening CFCS quartile $(p=0.001$, see online supplementary figure $E 4 B)$.

When the subgroup of patients with a normal $\mathrm{FEV}_{1}$ was analysed $(n=53)$, a difference in time to first PE among the LCI quartiles persisted $(p=0.047$, figure $3 C$ ), although this was not 
A

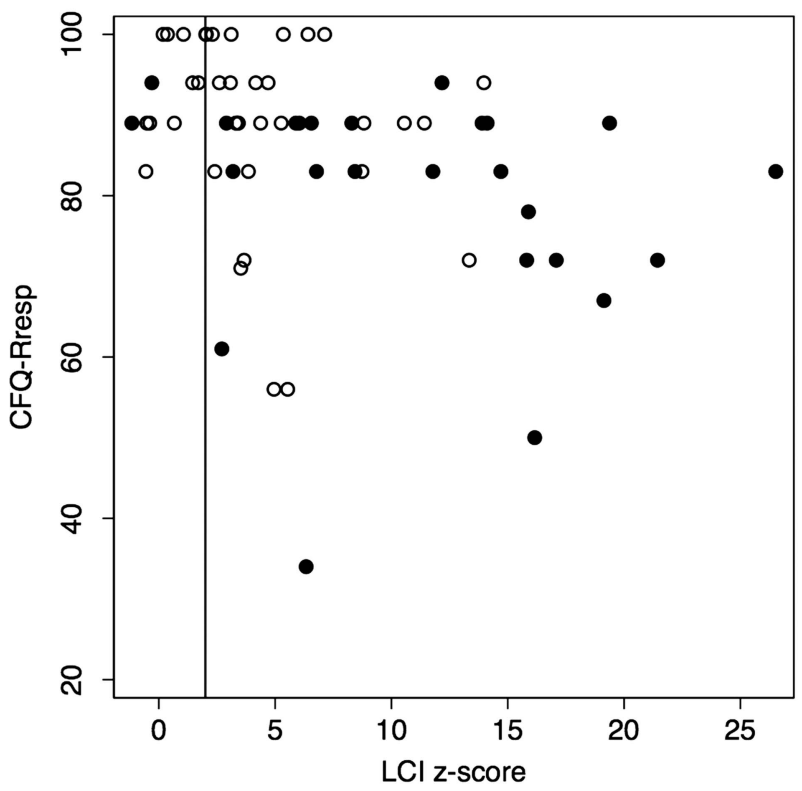

$\mathrm{C}$

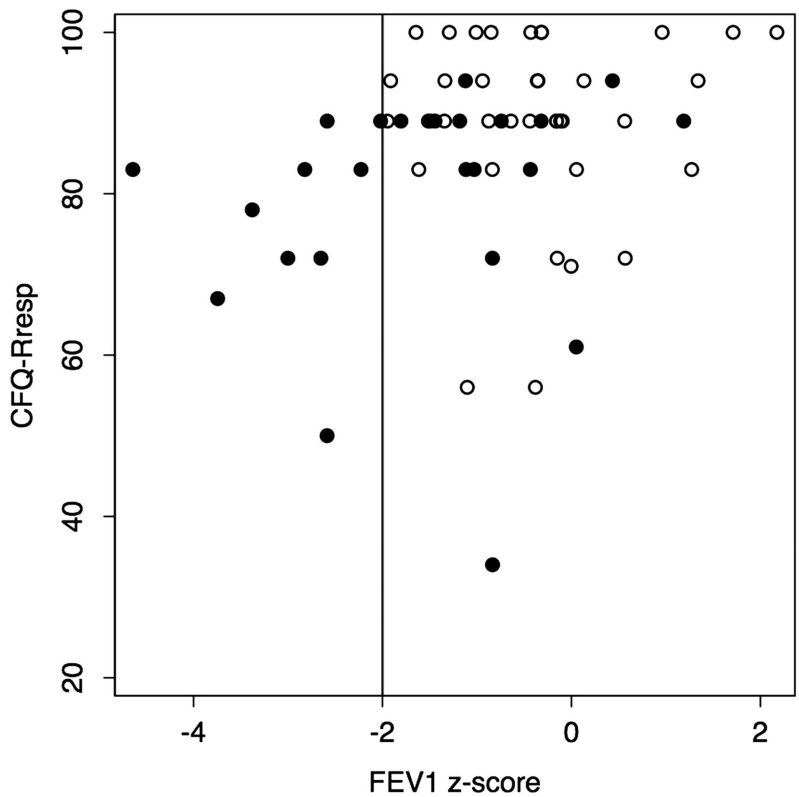

B

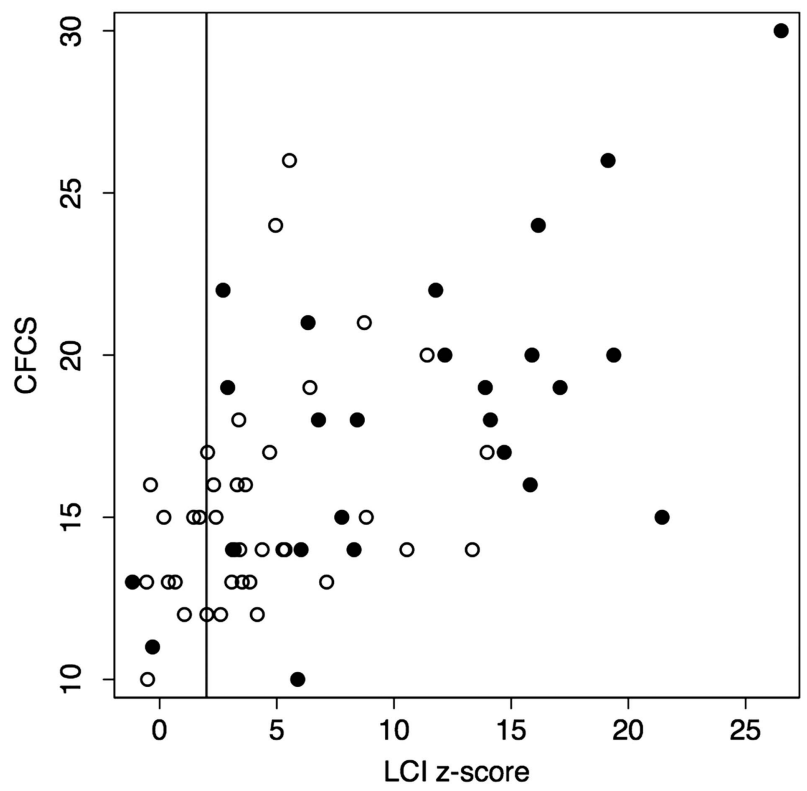

$\mathrm{D}$

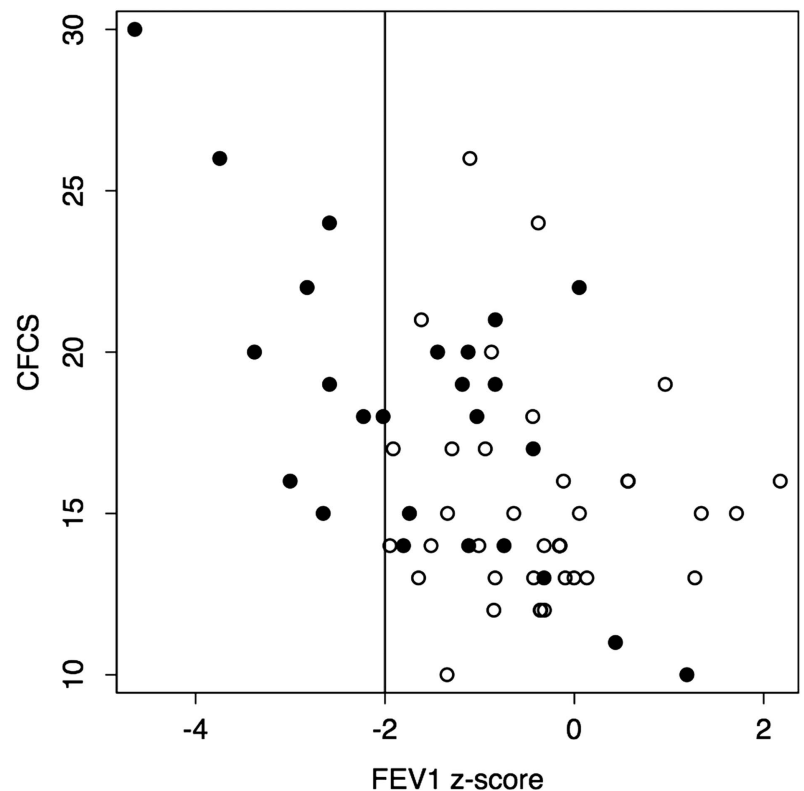

Figure 2 Correlations between the lung clearance index (LCI) z-score and (A) the respiratory domain of the Cystic Fibrosis Questionnaire-Revised $\left(\right.$ CFQ- $\left.\mathrm{R}_{\text {resp }}\right)$ and (B) the Cystic Fibrosis Clinical Score (CFCS) and between the forced expiratory volume in $1 \mathrm{~s}\left(\mathrm{FEV}\right.$ ) $\mathrm{z}$-score and (C) the CFQ- $\mathrm{R}_{\text {resp }}$ (D) and the CFCS in patients with cystic fibrosis with pulmonary exacerbation (closed circles) or without pulmonary exacerbation (open circles). The vertical line represents the upper limit of normal for the $\mathrm{LCl} z$-score (A and B) or the lower limit of normal for the $\mathrm{FEV}_{1} \mathrm{z}$-score (C and D).

observed for the $\mathrm{FEV}_{1} \mathrm{z}$-score quartiles $(\mathrm{p}=0.113$, figure $3 \mathrm{D})$ or among the $\mathrm{FEF}_{25-75} \mathrm{z}$-score quartiles $(\mathrm{p}=0.452$, see online supplementary figure E3B).

The univariate regression analysis (table 2) showed that the annual PE rate was higher among patients in the worst quartile compared with those in the best quartile for LCI $(\mathrm{p}=0.003)$. This difference was also observed when comparing the $\mathrm{FEV}_{1}$ $(p=0.016)$ or $\mathrm{FEF}_{25-75} \mathrm{z}$-score quartiles $(\mathrm{p}=0.020)$. Restricting the analysis to the subgroup of patients with a normal $\mathrm{FEV}_{1}$, the patients in the worst LCI quartile still had a higher PE rate than those in the best LCI quartile $(p=0.043)$, whereas the PE rate was not different between patients in the worst $\mathrm{FEV}_{1}$ z-score quartile $(\mathrm{p}=0.280)$ or $\mathrm{FEF}_{25-75}$ quartile $(\mathrm{p}=0.453)$ compared with those in the best quartiles.
Age, isolation of $P$ aeruginosa in the previous year, LCI z-score, $\mathrm{FEV}_{1}$ z-score, $\mathrm{FEF}_{25-75}$ z-score, CFCS and CFQ- $\mathrm{R}_{\text {resp }}$ were used as predictors for the multivariate prediction model because they were found to be significant predictors of the PE rate in the univariate analysis (table 3). The backward stepwise approach identified the LCI z-score $(p=0.001)$ as the only independent predictor of the PE rate in the year following the baseline assessment. An increase in the LCI z-score of 1 resulted in an increase in the PE rate by $12.0 \%(95 \%$ CI $5.0 \%$ to $19.5 \%)$. Restricting the analysis to patients with a normal $\mathrm{FEV}_{1}$, the LCI z-score remained a predictor of the PE rate in the following year (rate ratio (RR) $1.12,95 \%$ CI 1.02 to $1.23, \mathrm{p}=0.017$ ) and a trend was shown for the $\mathrm{FEV}_{1} \mathrm{z}$-score (RR $0.57,95 \%$ CI 0.31 to 1.07 , 


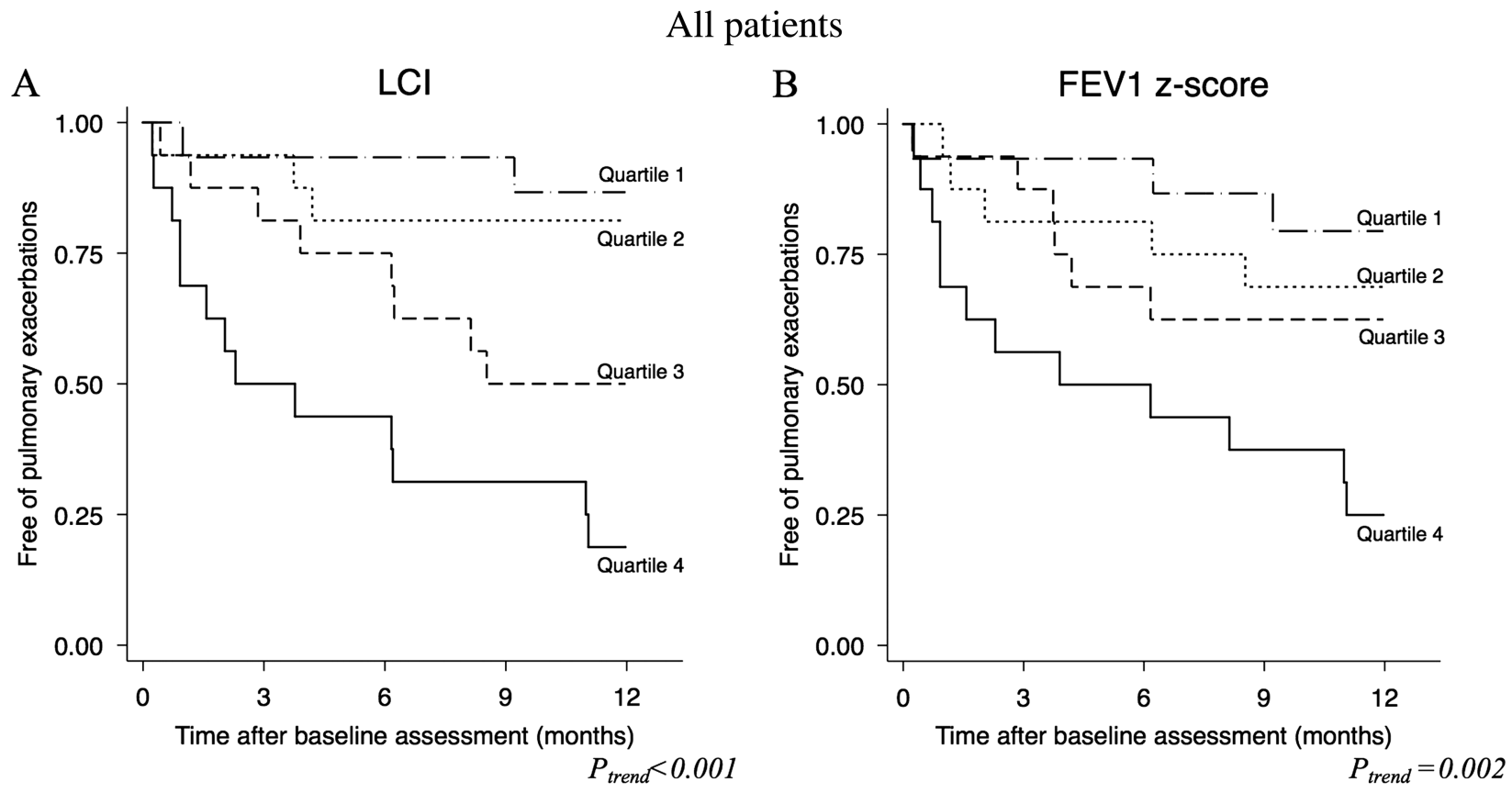

\section{Patients with normal $\mathrm{FEV}_{1}$}

$\mathrm{C}$

\section{$\mathrm{LCl}$}

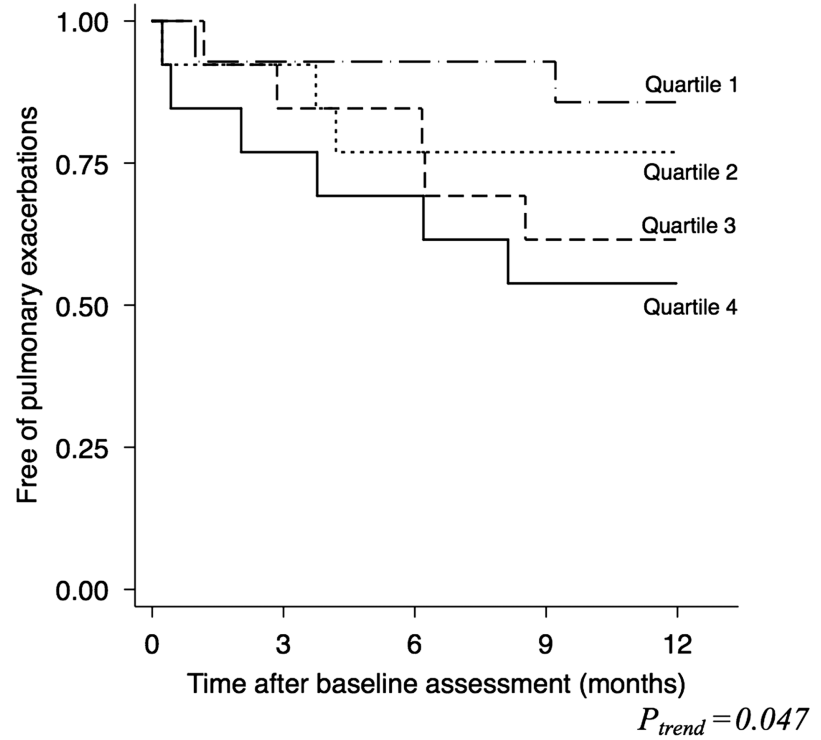

$\mathrm{D}$

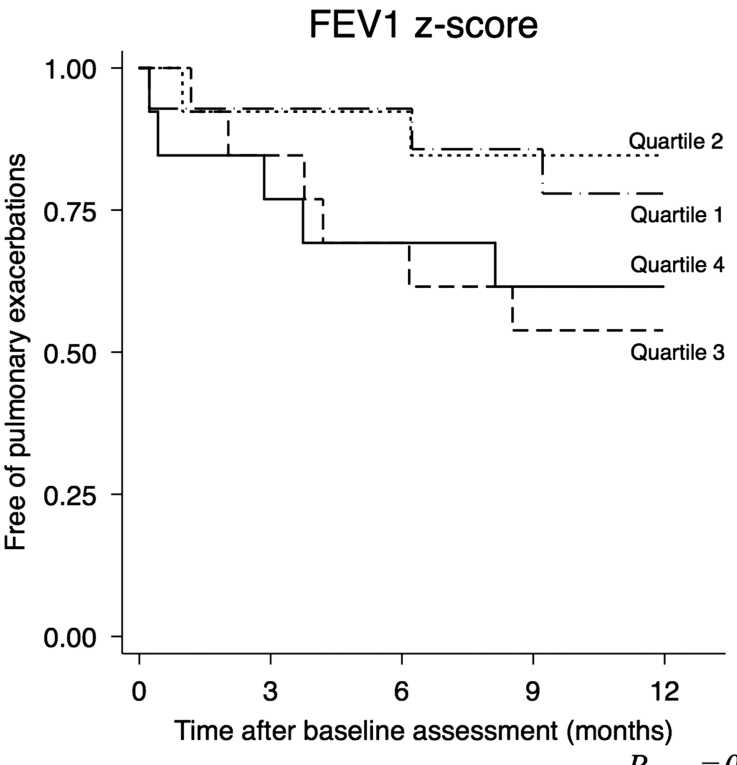

$P_{\text {trend }}=0.130$

Figure 3 Kaplan-Meier plots for the time to the first pulmonary exacerbation $(\mathrm{PE})$ after the baseline measurement. The subjects are grouped by quartiles of the lung clearance index $(\mathrm{LCl})(\mathrm{A}$ and $\mathrm{C})$ and forced expiratory volume in $1 \mathrm{~s}\left(\mathrm{FEV}_{1}\right) \mathrm{z}$-scores $(B$ and $\mathrm{D})$. In the upper plots $(A$ and $B)$, all subjects were included. In the bottom plots $(C$ and $D)$, only subjects with a normal FEV 1 were included (see table E2 in the online supplement for the definitions of the quartiles). $p$ Values from the log-rank test for trend are shown.

$\mathrm{p}=0.077)$ and the $\mathrm{FEF}_{25-75} \mathrm{z}$-score (RR $0.72,95 \%$ CI 0.47 to $1.11, \mathrm{p}=0.134)$.

\section{DISCUSSION}

In the present study we have demonstrated a clear association between the baseline LCI and subsequent PEs in a cohort of 519-year-old patients with CF. We also documented a correlation between the LCI and the CFQ- $\mathrm{R}_{\text {resp }}$, a validated patientreported outcome. This result demonstrates the association between the LCI and clinically meaningful endpoints, which is a necessary step in the validation of LCI as a surrogate endpoint for clinical trials involving patients with CF. In the subgroup of patients with a normal $\mathrm{FEV}_{1}$, the LCI was more closely related to PEs and CFQ- $\mathrm{R}_{\text {resp }}$ than were $\mathrm{FEV}_{1}$ and $\mathrm{FEF}_{25-75}$, highlighting the added value of the LCI over $\mathrm{FEV}_{1}$ and $\mathrm{FEF}_{25-75}$ in the group of patients with early CF lung disease.

\section{$\mathrm{LCl}$ and PEs}

The cohort included in this study is representative of the current spectrum of lung disease in children and young adults 
Table 2 Annual rate of PEs and rate ratios (RRs) from the univariate negative binomial regression models by quartiles of $L C l$ and $F E V_{1} z-s c o r e s$ in all patients and in patients with a normal $\mathrm{FEV}_{1}$

\begin{tabular}{|c|c|c|c|c|c|c|c|c|c|}
\hline \multicolumn{5}{|c|}{ All patients $(n=63)$} & \multicolumn{5}{|c|}{ Patients with normal FEV ${ }_{1}(n=53)$} \\
\hline Parameter & $\begin{array}{l}\text { Annual } \mathrm{PE} \\
\text { rate }(95 \% \mathrm{Cl})\end{array}$ & p Value* & RR (95\% CI) & p Value* & Parameter & $\begin{array}{l}\text { Annual } \mathrm{PE} \\
\text { rate }(95 \% \mathrm{CI})\end{array}$ & p Value* & RR $(95 \% \mathrm{CI})$ & p Value* \\
\hline LCl z-score & & & & & LCl z-score & & & & \\
\hline$\leq 2.4$ & $0.1(0.0-0.6)$ & & 1 & & $\leq 2.3$ & $0.1(0.0-0.6)$ & & 1 & \\
\hline $2.6-5.0$ & $0.4(0.1-1.0)$ & 0.088 & $2.9(0.5-16.5)$ & 0.238 & $2.4-3.9$ & $0.5(0.2-1.2)$ & 0.462 & $3.3(0.6-19.04)$ & 0.186 \\
\hline $5.3-10.6$ & $0.7(0.3-1.6)$ & 0.016 & $5.4(1.0-29.0)$ & 0.045 & $4.2-6.8$ & $0.6(0.2-1.5)$ & 0.302 & $4.1(0.7-23.4)$ & 0.114 \\
\hline$\geq 11.4$ & $1.8(1.0-3.3)$ & 0.003 & $13.6(2.8-67.1)$ & 0.001 & $\geq 7.1$ & $0.9(0.4-2.0)$ & 0.043 & $6.5(1.2-34.5)$ & 0.029 \\
\hline $\mathrm{FEV}_{1}$ z-score & & & & & $\mathrm{FEV}_{1}$ z-score & & & & \\
\hline$>=-0.1$ & $0.3(0.1-0.8)$ & & 1 & & $>=0.1$ & $0.3(0.1-0.9)$ & & 1 & \\
\hline$-0.8--0.2$ & $0.6(0.3-1.4)$ & 0.130 & $2.3(0.6-9.0)$ & 0.228 & $-0.4--0.1$ & $0.2(0.0-0.7)$ & 0.488 & $0.5(0.1-3.4)$ & 0.499 \\
\hline$-1.5--0.8$ & $0.7(0.3-1.5)$ & 0.111 & $2.4(0.6-9.5)$ & 0.200 & $-1.1--0.6$ & $1.0(0.5-2.2)$ & 0.114 & $3.4(0.9-13.3)$ & 0.073 \\
\hline$\leq-1.6$ & $1.5(0.8-2.8)$ & 0.016 & $5.5(1.5-19.6)$ & 0.009 & $\leq-1.2$ & $0.7(0.3-1.6)$ & 0.280 & $2.3(0.5-9.4)$ & 0.260 \\
\hline
\end{tabular}

with CF. The majority of our patients had a normal $\mathrm{FEV}_{1}$, as observed in most Western countries, but an abnormal LCI. All children with a normal LCI had a normal $\mathrm{FEV}_{1}$, which is in line with the expected superior sensitivity of the LCI to detect early lung disease. ${ }^{8}$ At the severe end of the spectrum of lung function abnormalities, PEs were predicted by $\mathrm{FEV}_{1}$ as all patients with an abnormal $\mathrm{FEV}_{1}$ had at least one $\mathrm{PE}$ in the 1-year follow-up period. This observation was not unexpected because $\mathrm{FEV}_{1}$ is one of the major determinants of $\mathrm{PE},{ }^{24}$ and clinicians take $\mathrm{FEV}_{1}$ into account when deciding whether a patient needs additional treatment. ${ }^{19}$ In this study the clinicians were blinded to the LCI values to avoid changes in the threshold for treating patients with intravenous antibiotics. Despite this blinding, LCI was a good predictor of PEs in patients with a normal $\mathrm{FEV}_{1}$. Only two of 11 patients with a normal LCI were treated with intravenous antibiotics for a PE: one patient was a 10 -year-old boy with an eventual diagnosis of allergic bronchopulmonary aspergillosis and the other was a 17-year-old girl with mild symptoms and no significant change in $\mathrm{FEV}_{1}$, weight or LCI before and after treatment with intravenous antibiotics. In the multivariate analysis, LCI remained as the single predictor of PE. It should be highlighted that, as LCI, $\mathrm{FEV}_{1}$ and $\mathrm{FEF}_{25-75}$

Table 3 Univariate negative binomial regression models for pulmonary exacerbations in the year following the baseline measurement

\begin{tabular}{lrllllll}
\hline Predictor & $\boldsymbol{\beta}$ & $\begin{array}{l}\text { SE } \\
(\boldsymbol{\beta})\end{array}$ & $\begin{array}{l}\text { Wald } \\
\boldsymbol{\chi}^{2}\end{array}$ & $\begin{array}{l}\boldsymbol{p} \\
\text { Value }\end{array}$ & $\begin{array}{l}\text { Rate } \\
\text { ratio }\end{array}$ & $\begin{array}{l}\text { 95\% Cl of } \\
\text { rate ratio }\end{array}$ \\
\hline LCl z-score & 0.11 & 0.03 & 11.9 & 0.001 & 1.12 & 1.05 & 1.19 \\
FEV $_{1}$ z-score & -0.54 & 0.17 & 10.3 & 0.001 & 0.58 & 0.42 & 0.81 \\
CFCS $_{\text {FEF }}$ & 0.15 & 0.05 & 8.3 & 0.004 & 1.16 & 1.05 & 1.29 \\
Z-score & -0.38 & 0.13 & 8.3 & 0.004 & 0.69 & 0.53 & 0.89 \\
Ps.a positive* & 0.90 & 0.40 & 5.5 & 0.023 & 2.46 & 1.13 & 5.36 \\
CFQ-R & -0.03 & 0.01 & 5.3 & 0.021 & 0.97 & 0.94 & 0.99 \\
Age in years & 0.10 & 0.05 & 3.9 & 0.049 & 1.10 & 1.00 & 1.22 \\
Female gender & 0.50 & 0.39 & 1.6 & 0.199 & 1.65 & 0.77 & 3.53 \\
\hline
\end{tabular}

${ }^{*} \geq 1$ positive culture for Pseudomonas aeruginosa in the 12 months preceding the baseline measurement.

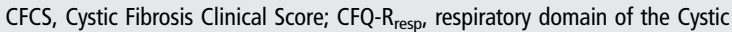
Fibrosis Questionnaire-Revised; $\mathrm{FEF}_{25-75}$, forced expiratory flow between $25 \%$ and $75 \%$ of forced vital capacity; FEV clearance index; Ps.a, Pseudomonas aeruginosa. are correlated, one of these spirometric parameters could have been excluded from the multivariate model because colinearity decreases the power of the analysis to detect significant predictors. Ideally, the model should have been built from a fraction of the dataset and validated in the remaining data. Due to limited number of subjects, this could not be applied in the present study.

As there is no universally accepted definition for $\mathrm{PE}^{25}$ we chose to use a conservative definition including only episodes treated with intravenous antibiotics. PEs treated with intravenous antibiotics are known to have an impact on long-term outcomes $^{26}$ and patient-reported outcomes, ${ }^{27}$ which suggests that our definition of PE represented a relevant clinical outcome. Episodes of treatment with oral antibiotics were not considered in the present study as their impact on outcomes has not been established and because oral antibiotics are also prescribed for positive airway cultures, regardless of clinical symptoms. The decision to administer intravenous antibiotics was made during multidisciplinary team meetings in a single centre, thereby minimising the differences in practice among physicians. Using this definition, $40 \%$ of our patients experienced a PE, which is in line with previously published data in similar age cohorts. ${ }^{24}$

\section{Patient-reported outcomes}

Correlations with patient-reported outcomes have been reported for $\mathrm{FEV}_{1}{ }^{28}$ total $\mathrm{CT}$ score ${ }^{29}$ and bronchiectasis and air trapping scores. ${ }^{30}$ Data on the correlations among LCI, symptoms and patient-reported outcomes are sparse. Bakker et al ${ }^{31}$ measured the LCI and cough counts over two nights in preschool children with CF and found no correlation between these variables. Aurora $e t a l^{15}$ found a correlation between the LCI and recent cough in preschool children with CF. However, the study by Amin et $a l^{12}$ found no correlation between the LCI and the CFQ- $R_{\text {resp }}$ in a small group of patients. We showed that the LCI correlated with the CFQ- $\mathrm{R}_{\text {resp }}$ even in the group with a normal $\mathrm{FEV}_{1}$ even though $\mathrm{FEV}_{1}$ did not, which again highlights the superiority of LCI over $\mathrm{FEV}_{1}$ at the milder end of the CF disease spectrum.

Whether other spirometric indices such as the maximum expiratory flow at $50 \%$ of $\mathrm{FVC}^{32}$ forced expiratory flow at $75 \%$ of $\mathrm{FVC}^{833}$ and $\mathrm{FEF}_{25-75}{ }^{12}$ could be more sensitive for early CF lung disease than $\mathrm{FEV}_{1}$ has been debated. In the present cohort only a minority of patients (6 of 53) with a normal $\mathrm{FEV}_{1}$ had an 
abnormal $\mathrm{FEF}_{25-75}$, suggesting that $\mathrm{FEF}_{25-75}$ adds little information to that provided by $\mathrm{FEV}_{1}$. In addition, $\mathrm{FEF}_{25-75}$ correlated with CFQ- $\mathrm{R}_{\text {resp }}$ and was predictive of PE but, unlike LCI, was not a predictor of $\mathrm{PE}$ in patients with a normal $\mathrm{FEV}_{1}$.

\section{Future developments}

Demonstrating a relationship with subsequent mortality would validate the LCI as a surrogate outcome measure. However, whether initial disease progression as shown by changes in the LCI at a younger age will continue during adulthood and lead to an untimely death remains unclear although, in adults, the LCI has been correlated with $\mathrm{FEV}_{1}$, ${ }^{34}$ a strong predictor of mortality. ${ }^{35}$

After establishment of the prognostic value of LCI for occurrence of PEs, more information is needed about fluctuations of LCI in patients with CF, the effect of exacerbations on LCI and the timing and magnitude of LCI improvement with interventions to determine what represents a clinically meaningful change.

The present study was at a single centre and the results may need to be replicated by other teams. With the advent of commercially available tools to measure LCI and the standardisation of its measurements and calculations, more centres will probably measure the LCI as part of their routine evaluation in patients with CF, providing 'real-life' longitudinal data on the long-term significance of LCI.

This study was not designed to explore whether or how LCI can be used to guide therapeutic decisions in an individual patient. It is not known how much decline would indicate the need for additional treatment or how much increase would constitute a significant improvement.

The placement of the LCI in the outcome toolbox requires further refinement, and it needs to be evaluated how this measure compares with other surrogate outcomes such as the chest CT scan score. However, the LCI appears to fit well as an endpoint in children with $\mathrm{CF}$ and mild lung disease in whom $\mathrm{FEV}_{1}$ lacks sensitivity and in whom the need for repeated measurements contraindicates chest CT due to radiation risks.

In conclusion, the present study shows that the LCI is predictive of PE and is related to patient-reported outcomes and symptoms in 5-19-year-old patients with CF, even in the subgroup with a normal $\mathrm{FEV}_{1}$. These results add to the validation of the LCI as a surrogate endpoint for use in clinical trials.

Acknowledgements The authors thank the children and families participating in the study. They also thank Kris Colpaert, Linda Boulanger, Nathalie Feyaerts and Jill Ophoff for technical assistance and help with data collection and management.

Contributors Acquisition of data: FV, MP, MB and KDB. Analysis and interpretation of data: FV and KDB. Drafting or revising the paper for important intellectual content and final approval of the paper: FV, MP, MB, TH and KDB.

Funding This study was supported by a grant from the 'Belgische Vereniging voor de Strijd tegen Mucoviscidose' and 'Klinisch Onderzoeksfonds'.

Competing interests None.

Ethics approval The study was approved by the ethics committee of the University of Leuven.

Provenance and peer review Not commissioned; externally peer reviewed.

\section{REFERENCES}

1 Corey M. Power considerations for studies of lung function in cystic fibrosis. Proc Am Thorac Soc 2007;4:334-7.

2 Fuchs SI, Ellemunter $\mathrm{H}$, Eder J, et al. Feasibility and variability of measuring the Lung Clearance Index in a multi-center setting. Pediatr Pulmonol 2012;47:649-57.

3 Singer $F$, Kieninger $E$, Abbas $C$, et al. Practicability of nitrogen multiple-breath washout measurements in a pediatric cystic fibrosis outpatient setting. Pediatr Pulmonol 2013;48:739-46.

4 Robinson PD, Latzin P, Verbanck $S$, et al. Consensus statement for inert gas washout measurement using multiple- and single- breath tests. Eur Respir J 2013;41:507-22
5 Singer $F$, Houltz $B$, Latzin $P$, et al. A realistic validation study of a new nitrogen multiple-breath washout system. PLoS One 2012;7:e36083.

6 Fuchs $\mathrm{SI}$, Sturz J, Junge $S$, et al. A novel sidestream ultrasonic flow sensor for multiple breath washout in children. Pediatr Pulmonol 2008;43:731-8.

7 Fuchs SI, Eder J, Ellemunter $\mathrm{H}$, et al. Lung clearance index: normal values, repeatability, and reproducibility in healthy children and adolescents. Pediatr Pulmonol 2009:44:1180-5.

8 Gustafsson PM, De Jong PA, Tiddens HA, et al. Multiple-breath inert gas washout and spirometry versus structural lung disease in cystic fibrosis. Thorax 2008;63:129-34.

9 Owens CM, Aurora P, Stanojevic S, et al. Lung Clearance Index and HRCT are complementary markers of lung abnormalities in young children with CF. Thorax 2011;66:481-8.

10 Robinson PD, Cooper P, Van Asperen P, et al. Using index of ventilation to assess response to treatment for acute pulmonary exacerbation in children with cystic fibrosis. Pediatr Pulmonol 2009;44:733-42.

11 Amin $\mathrm{R}$, Subbarao $\mathrm{P}$, Jabar $\mathrm{A}$, et al. Hypertonic saline improves the $\mathrm{LCl}$ in paediatric patients with CF with normal lung function. Thorax 2010;65:379-83.

12 Amin $R$, Subbarao $P$, Lou $W$, et al. The effect of dornase alfa on ventilation inhomogeneity in patients with cystic fibrosis. Eur Respir J 2011;37:806-12.

13 Subbarao P, Stanojevic S, Brown M, et al. Lung clearance index as an outcome measure for clinical trials in young children with cystic fibrosis: a pilot study using inhaled hypertonic saline. Am J Respir Crit Care Med 2013;188:456-60.

14 Davies JC, Sheridan H, Lee P-S, et al. Effect of ivacaftor on lung function in subjects with cystic fibrosis who have the G551D-CFTR mutation and mild lung disease : a comparison of lung clearance index ( $\mathrm{LCl}$ ) vs. spirometry [abstract]. J Cyst Fibros 2012;11(Suppl 1):S15.

15 Aurora $\mathrm{P}$, Stanojevic S, Wade A, et al. Lung clearance index at 4 years predicts subsequent lung function in children with cystic fibrosis. Am J Respir Crit Care Med 2011;183:752-8.

16 Vermeulen $\mathrm{F}$, Ophoff J, Proesmans $\mathrm{M}$, et al. Does lung clearance index predict time to pulmonary excerbation? J Cyst Fibros 2012;11(Suppl 1):S14.

17 Quanjer PH, Stanojevic S, Cole TJ, et al. Multi-ethnic reference values for spirometry for the 3-95-yr age range: the global lung function 2012 equations. Eur Respir J 2012:40:1324-43.

18 Roelants M, Hauspie R, Hoppenbrouwers K. References for growth and pubertal development from birth to 21 years in Flanders, Belgium. Ann Hum Biol 2009;36:680-94.

19 Smyth A, Elborn JS. Exacerbations in cystic fibrosis: 3-Management. Thorax 2008;63:180-4.

20 Quittner AL, Sawicki GS, McMullen A, et al. Psychometric evaluation of the Cystic Fibrosis Questionnaire-Revised in a national sample. Qual Life Res 2012;21:1267-78.

21 Klijn PH, van Stel HF, Quittner AL, et al. Validation of the Dutch cystic fibrosis questionnaire (CFQ) in adolescents and adults. J Cyst Fibros 2004;3:29-36.

22 Kanga J, Kuhn R, Craigmyle L, et al. Cystic fibrosis clinical score: a new scoring system to evaluate acute pulmonary exacerbation. Clin Ther 1999;21:1343-56.

23 Lee TW, Brownlee KG, Conway SP, et al. Evaluation of a new definition for chronic Pseudomonas aeruginosa infection in cystic fibrosis patients. J Cyst Fibros 2003;2:29-34

24 Goss $\mathrm{CH}$, Burns JL. Exacerbations in cystic fibrosis. 1: Epidemiology and pathogenesis. Thorax 2007;62:360-7

25 Bilton D, Canny G, Conway S, et al. Pulmonary exacerbation: towards a definition for use in clinical trials. Report from the EuroCareCF Working Group on outcome parameters in clinical trials. J Cyst Fibros 2011;10(Suppl 2):S79-81.

26 Waters V, Stanojevic S, Atenafu EG, et al. Effect of pulmonary exacerbations on long-term lung function decline in cystic fibrosis. Eur Respir J 2012;40:61-6.

27 Hegarty M, Macdonald J, Watter $\mathrm{P}$, et al. Quality of life in young people with cystic fibrosis: effects of hospitalization, age and gender, and differences in parent/child perceptions. Child Care Health Dev 2009;35:462-8.

28 Quittner AL, Schechter MS, Rasouliyan L, et al. Impact of socioeconomic status, race, and ethnicity on quality of life in patients with cystic fibrosis in the United States. Chest 2010;137:642-50.

29 Loeve M, Gerbrands K, Hop WC, et al. Bronchiectasis and pulmonary exacerbations in children and young adults with cystic fibrosis. Chest 2011;140:178-85.

30 Tepper LA, Utens E, Caudri D, et al. Impact of bronchiectasis and trapped air on quality of life and exacerbations in CF. Eur Respir J 2013:42:371-9.

31 Bakker EM, van der Meijden JC, Nieuwhof EM, et al. Determining presence of lung disease in young children with cystic fibrosis: lung clearance index, oxygen saturation and cough frequency. J Cyst Fibros 2012;11:223-30.

32 Kraemer $R$, Blum A, Schibler A, et al. Ventilation inhomogeneities in relation to standard lung function in patients with cystic fibrosis. Am J Respir Crit Care Med 2005;171:371-8.

33 Bakker EM, Borsboom GJ, van der Wiel-Kooij EC, et al. Small airway involvement in cystic fibrosis lung disease: routine spirometry as an early and sensitive marker. Pediatr Pulmonol Published Online First: 13 Feb 2013. doi: 10.1002/ppul.22777.

34 Horsley AR, Gustafsson PM, Macleod KA, et al. Lung clearance index is a sensitive, repeatable and practical measure of airways disease in adults with cystic fibrosis. Thorax 2008:63:135-40.

35 Corey M, Farewell V. Determinants of mortality from cystic fibrosis in Canada, 1970-1989. Am J Epidemiol 1996:143:1007-17. 